\title{
Comunicação
}

\section{Desempenho de cultivares nacionais de batata para produtividade de tubérculos}

\author{
Giovani Olegario da Silva ${ }^{1}$, Antonio César Bortoletto ${ }^{2}$, Rubens Ponijaleki ${ }^{3}$ \\ Atila Francisco Mogor ${ }^{4}$, Arione da Silva Pereira \\ http://dx.doi.org/10.1590/0034-737X201461050020
}

\section{RESUMO}

O objetivo deste trabalho foi verificar o desempenho dos cultivares de batata nacionais BRS Ana e BRS Clara, em comparação com os cultivares importados Ágata e Asterix, em relação à produtividade de tubérculos. Os experimentos foram realizados no município de Canoinhas, SC. Foram avaliados quatro cultivares de batata: BRS Ana, BRS Clara, Asterix e Ágata. O delineamento experimental foi em blocos casualizados, com quatro repetições. As parcelas continham quatro linhas com 20 plantas em cada linha. Cento e dez dias após o plantio foi realizada a colheita e, os tubérculos de cada parcela, avaliados para caracteres relacionados com a produtividade de tubérculos. Os dados foram submetidos à análise de variância e agrupamento de médias, por Skott \& Knott, a 5\% de probabilidade. Os cultivares de batata nacionais BRS Ana e BRS Clara foram mais produtivos do que os importados Asterix e Ágata; no entanto, são mais tardios, quanto ao ciclo vegetativo.

Palavras-chave: Solanum tuberosum L., caracteres de tubérculo, BRS Clara, BRS Ana, Ágata, Asterix.

\section{ABSTRACT}

\section{Performance of Brazilian potato cultivars for tuber yield}

The objective of this study was to evaluate the performance of Brazilian potato cultivars, BRS Ana and BRS Clara, compared with the imported cultivars Ágata and Asterix, for tuber yield characters. The experiments were carried out in Canoinhas, State of Santa Catarina.Four potato cultivars were evaluated: BRS Ana, BRS Clara, Asterix and Ágata. The experimental design was randomized blocks with four replicates. Plots consisted of four rows with 20 plants in each row. The tubers of each plot were harvested and evaluated for traits related to tuber yield 110 days after planting. Data were submitted to analysis of variance and grouping of means by Skott \& Knott at 5\% of probability.Brazilian potato cultivars BRS Ana and BRS Clara provided higher yields than the imported Asterix and Ágata. On the other hand, they are later regarding the vegetative cycle.

Key words:Ágata, Asterix, BRS Clara, BRS Ana,Solanum tuberosum L., tuber characters

\footnotetext{
Recebido para publicação em 14/06/2013 e aprovado em 29/07/2014.

'Engenheiro-Agrônomo, Doutor. Embrapa Hortaliças, Rodovia BR 280, Km 231, 1151, Caixa Postal 317, 89460-000, Canoinhas, Santa Catarina, Brasil. giovani.olegario@embrapa.br (autor para correspondência).

2Engenheiro-Agrônomo. Embrapa Produtos e Mercado, Rodovia BR 280, Km 231, 1151, Caixa Postal 317, 89460-000, Canoinhas, Santa Catarina, Brasil. antonio.bortoletto@embrapa.br ${ }^{3}$ Técnico Agrícola. Embrapa Produtos e Mercado, Rodovia BR 280, Km 231, 1151, Caixa Postal 317, 89460-000, Canoinhas, Santa Catarina, Brasil. rubens.ponijaleki@embrapa.br ${ }^{4}$ Engenheiro-Agrônomo, Doutor. Universidade Federal do Paraná, Rua XV de Novembro, 1299, 80060-000, Curitiba, Paraná, Brasil. atila.mogor@ufpr.br

${ }^{5}$ Engenheiro-Agrônomo, Doutor. Embrapa Clima Temperado, Rodovia BR 392, Km 78, Caixa Postal 403, 96001-970, Pelotas, Rio Grande do Sul, Brasil. arione.pereira@embrapa.br
} 


\section{INTRODUÇÃO}

A batata (Solanum tuberosum L.) é considerada a terceira fonte alimentar da humanidade, sendo suplantada pelo arroz e trigo, já que o milho é mais utilizado em nutrição animal. Originária da região dos altiplanos andinos da América do Sul, a batata já era cultivada e consumida pelos povos da região, há mais de 7.000 anos. Somente em meados do século XVI foi introduzida na Europa, onde se popularizou, difundindo-se daí para os outros continentes (Love et al., 2003). Cultivada em mais de 125 países, a produção mundial de batata é da ordem de 332,3 milhões de toneladas, com área plantada de 18,2 milhões de hectares e produtividade média de 18,3 $\mathrm{t} \mathrm{ha}^{-1}$. Em 2012, foram plantados, no Brasil, 130,402 mil hectares, com produção de 3,5 milhões de toneladas, alcançando a produtividade média de 26,9 t ha $^{-1}$ (Agrianual, 2013).

A maior parte dos cultivares de batata utilizados atualmente no Brasil foram desenvolvidos na Europa. Entretanto, a produtividade, nas condições brasileiras de clima e solo, são inferiores em comparação com as dos países de origem (Resende et al., 1999), por esses cultivares terem sido selecionados sob condições de fotoperíodo longo e baixa pressão de alguns fatores bióticos, que afetam a cultura, no Brasil. Tais cultivares, quando plantados nas condições subtropicais e tropicais do País, apresentam período vegetativo menor (Rodrigues, 2006) e, por conseguinte, menor produção de fotoassimilados. Para conseguir alto rendimento, é necessária a utilização de grande quantidade de insumos, o que pode ocasionar menor sustentabilidade do sistema de produção. Desta forma, a obtenção de cultivares nacionais, adaptados às condições de cultivo, nas diversas regiões produtoras brasileiras, com resistência às principais doenças, é a alternativa mais viável para tornar a cultura mais produtiva e rentável (Gadum et al., 2003).

O grande desafio dos melhoristas de batata consiste em disponibilizar, constantemente, novos cultivares, que atendam às exigências crescentes: 1) dos consumidores, quanto às qualidades visual e culinária do produto; 2) dos produtores, quanto à maior produtividade, aliada à precocidade; 3) das indústrias, quanto à qualidade da matéria-prima.

Tubérculos com aspecto visual atrativo são preferidos pelos consumidores. Cultivares que produzem tubérculos grandes, entre $45 \mathrm{~mm}$ e $85 \mathrm{~mm}$, trazem maior lucratividade ao produtor. Além de apresentarem maior produtividade de tubérculos por área de cultivo, possibilitam a classificação do produto em classes nobres (batata especial) que, consequentemente, alcançam melhor valor de mercado (Arimura et al., 2007). Os processadores demandam matéria-prima com características que ofereçam alto rendimento industrial e produto final de elevada qualidade e custo baixo; portanto, de alta produtividade.

No sentido de atender as demandas da cadeia brasileira da batata, por cultivares mais adaptados, o Programa de Melhoramento de Batata da Embrapa lançou os cultivares BRS Ana, em 2007, e BRS Clara, em 2010. O objetivo deste trabalho foi compará-los, com os cultivares mais plantados no país, quanto ao rendimento de tubérculos.

\section{MATERIAIS E MÉTODOS}

Foram avaliados quatro cultivares de batata: BRS Ana, BRS Clara, Ágata e Asterix. Os dois primeiros foram desenvolvidos pelo Programa de Melhoramento Genético de Batata da Embrapa e os outros dois foram gerados na Holanda.

O cultivar BRS Ana foi lançado em 2007, é adequado para fritura à francesa, para comercialização no mercado de produtos frescos e com potencial de uso no processamento industrial, na forma de palitos pré-fritos congelados (Pereira et al., 2010). Os tubérculos têm película vermelha, levemente áspera, polpa branca, formato oval e olhos rasos. Apresentam alto potencial produtivo e elevado peso específico. As plantas apresentam crescimento semiereto e porte e ciclo vegetativo tardio. Têm boa resistência a defeitos fisiológicos, são moderadamente susceptíveis à requeima (Phytophthora infestans), boa resistência à pinta-preta (Alternaria solani) e baixa degenerescência por vírus.

O 'BRS Clara' foi liberado para cultivo em 2010. É um cultivar de batata para mercado de produtos frescos, com resistência à requeima (Pereira et al., 2012). Os tubérculos têm película amarela lisa, polpa creme, formato oval-alongado e olhos rasos. O potencial produtivo é alto, com baixa incidência de defeitos fisiológicos. Os tubérculos apresentam peso específico médio. Sua aptidão culinária preferencial é para cozimento, para preparação de saladas. As plantas apresentam crescimento semiereto, porte e ciclo vegetativo médio, moderada a alta resistência à requeima, resistência moderada à pinta-preta e susceptibilidade a viroses.

Ágata é o principal cultivar de batata do país. De película amarela, destaca-se por apresentar elevado potencial produtivo, precocidade e boa aparência de tubérculos (Pinto et al., 2010; Fernandes et al., 2011). Apresenta dormência curta, tubérculos ovais, baixo teor de massa seca. Portanto, é recomendado apenas para o consumo na forma cozida. É susceptível às principais doenças que prejudicam a cultura no Brasil (Peeten et al., 2011). 
Asterix é o cultivar de película rosada mais cultivado no Brasil. Apresenta ciclo médio, com tubérculos alongados, olhos rasos e polpa amarelo-claro. É susceptível à requeima $\mathrm{e}$ a viroses, mas apresenta tolerância moderada à pinta preta (Alternaria solani). Sob estresse hídrico, apresenta tubérculos desuniformes em formato. Seu conteúdo de matéria seca é de médio a alto, sendo recomendado preferencialmente para fritura (Pereira et al., 2010).

Os experimentos foram realizados no campo experimental da Embrapa Produtos e Mercado, em Canoinhas, SC (26 $10^{\prime} 38^{\prime \prime} \mathrm{S}, 50^{\circ} 23^{\prime} 24^{\prime \prime} \mathrm{W}, 839 \mathrm{~m}$ de altitude), na primavera de 2011 e no outono de 2012. Em ambos os cultivos, o delineamento experimental foi em blocos casualizados, com quatro repetições e parcelas com 80 plantas, divididas em quatro linhas de 20 plantas cada. Para todos os cultivares, foram utilizadas sementes do tipo II, com quatro meses de armazenamento em câmara fria. Os tubérculos foram plantados com espaçamento de $0,70 \mathrm{~m}$, entre linhas, e $0,35 \mathrm{~m}$, entre plantas, nos dias 13 de agosto, para o cultivo de 2011, e 09 de fevereiro, para o cultivo de 2012, na mesma área experimental. Como fertilizantes foram utilizados, na base, distribuídos na linha de plantio, $600 \mathrm{~kg} \mathrm{ha}^{-1}$ de nitrato de amônio, $700 \mathrm{~kg} \mathrm{ha}^{-1}$ de superfosfato simples e 233,80 $\mathrm{kg} \mathrm{ha}^{-1} \mathrm{de}$ cloreto de potássio. Os tratos culturais e fitossanitários seguiram as recomendações da região (Pereira \& Daniels, 2003).

As colheitas ocorreram 110 dias após os plantios e os tubérculos de cada parcela foram avaliados para os seguintes caracteres: número de tubérculos comerciais por parcela (diâmetro transversal acima de $45 \mathrm{~mm}$ ); número total de tubérculos por parcela; massa de tubérculos comerciais (g parcela $\left.{ }^{-1}\right)$; massa total de tubérculos $\left(\mathrm{kg}\right.$ parcela $\left.^{-1}\right)$; massa média de tubérculos $(\mathrm{kg})$, obtida pela divisão da massa total pelo número total de tubérculos, e percentagem da massa de tubérculos comerciais, obtida pela divisão da massa de tubérculos comerciais pela massa total de tubérculos por parcela, multiplicado por 100 .

Os dados foram verificados, quanto à distribuição normal dos resíduos, por meio do teste de Lilliefors, e submetidos à análise de variância e de agrupamento de médias, por Skott \& Knott, com o programa Genes (Cruz, 2006).

\section{RESULTADOS E DISCUSSÃO}

A interação entre cultivar x épocas foi significativa, para todos os caracteres e, desta forma, as discussões foram feitas, considerando-se separadamente cada ano de cultivo. A análise de variância dos dados de cada cultivo revelou diferenças significativas, para todos os caracteres.
Os coeficientes de variação ambientais foram baixos, variando de $5,24 \%$, para número total de tubérculos, no outono de 2011 , a $19,15 \%$, para massa de tubérculos comerciais, nesse mesmo período, indicando boa precisão experimental (Tabela 1). Estes valores são semelhantes aos obtidos por Silva et al. (2006), com valores variando de 17,31 a $21,03 \%$, para os caracteres rendimento, número e massa média de tubérculos de batata. Valores semelhantes de coeficiente de variação foram verificados, ainda, por Bisognin et al. (2008), variando entre 16,19 e $25,60 \%$, para o caractere produtividade de tubérculos de clones de batata com diferentes tamanhos. Da mesma forma, Costa et al. (2007) citaram valores de 22,70 e 18,30\% para produtividade total e número total de tubérculos de clones de batata. Portanto, considerando-se que a produtividade de tubérculos é um caractere quantitativo e de grande influência ambiental (Silva et al., 2006), os coeficientes de variação estão dentro dos valores esperados.

A relação entre os coeficientes de variação genético e ambiental foi superior à unidade, para todos os caracteres, em ambos os cultivos, variando de 2,13\%, para massa de tubérculos comerciais, no outono de 2012, a $13,75 \%$, para percentagem de massa de tubérculos comerciais, na primavera de 2011, indicando a predominância de efeitos de ordem genética em relação aos ambientais (Tabela 1).

Considerando-se os cultivares de película rosa, BRS Ana e Asterix, que são indicados, principalmente, para fritura, pode-se verificar que, em ambos os cultivos, BRS Ana foi mais produtivo do que Asterix, em número, massa e percentagem de tubérculos comerciais, além de tubérculos com maior massa média e maior massa total de tubérculos em 2011 (Tabela 1). No entanto, pôde-se observar que 'BRS Ana' finalizou seu ciclo vegetativo por volta dos 110 dias após o plantio, enquanto 'Asterix' o completou aos 100 dias, em ambos os cultivos.

O mesmo foi verificado com relação aos cultivares de batata de película amarela, entre os quais BRS Clara foi mais produtivo do que Ágata, considerando-se a massa de tubérculos comerciais, a percentagem de massa de tubérculos comerciais, o número de tubérculos comerciais e a massa total de tubérculos, em 2012. 'BRS Clara' também produziu tubérculos com maior massa média, mas esta diferença foi significativa apenas para 2011 (Tabela 1). A finalização natural do ciclo vegetativo de 'Ágata' ocorreu por volta dos 90 dias após o plantio, enquanto, de 'BRS Clara', foi aos 100 dias, em ambos os cultivos.

BRS Ana é um cultivar tardio, com ciclo próximo a 110 dias, na região sul do Brasil, porém é conhecidamente muito produtivo e bastante tolerante à seca e a doenças como a pinta preta (Alternaria solani) e à re- 
Tabela 1. Médias para caracteres de rendimento e peso específico de tubérculos dos cultivares de batata BRS Ana, BRS Clara, Ágata e Asterix na primavera de 2011 e outono de 2012

\begin{tabular}{|c|c|c|c|c|c|c|}
\hline \multirow[t]{2}{*}{ Cultivar } & \multicolumn{2}{|c|}{$\begin{array}{l}\text { Massa de tubérculos } \\
\text { comerciais }\left(\mathrm{kg} \mathrm{ha}^{-1}\right)\end{array}$} & \multicolumn{2}{|c|}{$\begin{array}{l}\text { Massa total de tubérculos } \\
\qquad\left(\mathrm{kg} \mathrm{ha}^{-1}\right)\end{array}$} & \multicolumn{2}{|c|}{$\begin{array}{c}\text { Percentagem de massa de } \\
\text { tubérculos comerciais }\end{array}$} \\
\hline & Primavera/11 & Outono/12 & Primavera/11 & Outono/12 & Primavera/11 & Outono/12 \\
\hline BRS Ana & $28,63 \mathrm{a}^{1}$ & $9,88 \mathrm{a}$ & 34,96 a & $24,35 \mathrm{a}$ & $41,75 \mathrm{a}$ & $20,59 a$ \\
\hline Asterix & $7,52 \mathrm{~b}$ & $5,50 \mathrm{c}$ & $26,86 \mathrm{~b}$ & 26,36 a & $14,36 \mathrm{c}$ & $10,64 \mathrm{~b}$ \\
\hline BRS Clara & $7,22 \mathrm{~b}$ & $7,70 \mathrm{~b}$ & $22,75 \mathrm{c}$ & $20,82 \mathrm{~b}$ & $16,16 \mathrm{~b}$ & $18,87 \mathrm{a}$ \\
\hline Ágata & $2,93 \mathrm{c}$ & $3,39 \mathrm{~d}$ & $19,72 \mathrm{c}$ & $16,38 \mathrm{c}$ & $7,55 \mathrm{~d}$ & $10,75 \mathrm{~b}$ \\
\hline Média & 11,58 & 6,63 & 26,07 & 21,98 & 19,96 & 15,21 \\
\hline $\mathrm{CV}(\%)$ & 13,82 & 19,15 & 11,04 & 7,13 & 5,46 & 11,98 \\
\hline $\mathrm{CVg} / \mathrm{CV}$ & 7,20 & 2,13 & 2,24 & 2,74 & 13,75 & 2,84 \\
\hline \multirow[t]{2}{*}{ Cultivar } & \multicolumn{2}{|c|}{$\begin{array}{l}\text { Massa média } \\
\text { de tubérculo (g) }\end{array}$} & \multicolumn{2}{|c|}{$\begin{array}{l}\text { Número total de tubérculos } \\
\text { por parcela }\end{array}$} & \multicolumn{2}{|c|}{$\begin{array}{c}\text { Número detubérculos comerciais } \\
\text { por parcela }\end{array}$} \\
\hline & Primavera/11 & Outono/12 & Primavera/11 & Outono/12 & Primavera/11 & Outono/12 \\
\hline BRS Ana & $200,46 \mathrm{a}$ & $119,57 \mathrm{a}$ & $341,50 \mathrm{~d}$ & $399,25 \mathrm{c}$ & $199,00 \mathrm{a}$ & $76,75 b$ \\
\hline Asterix & $84,80 \mathrm{~b}$ & $89,61 \mathrm{~b}$ & $621,50 \mathrm{~b}$ & $578,25 \mathrm{a}$ & $77,50 \mathrm{~b}$ & $43,25 \mathrm{c}$ \\
\hline BRS Clara & $97,22 b$ & $72,91 \mathrm{c}$ & $463,00 \mathrm{c}$ & $559,25 \mathrm{a}$ & $67,75 \mathrm{~b}$ & $96,75 \mathrm{a}$ \\
\hline Ágata & $51,15 \mathrm{c}$ & $63,30 \mathrm{c}$ & $756,75 \mathrm{a}$ & $508,25 \mathrm{~b}$ & $36,00 \mathrm{c}$ & $31,50 \mathrm{~d}$ \\
\hline Média & 108,41 & 86,35 & 545,68 & 511,25 & 95,06 & 62,06 \\
\hline $\mathrm{CV}(\%)$ & 10,08 & 8,83 & 8,45 & 5,24 & 7,91 & 10,70 \\
\hline $\mathrm{CVg} / \mathrm{CV}$ & 6,09 & 3,66 & 3,90 & 2,95 & 9,49 & 4,49 \\
\hline
\end{tabular}

${ }^{1}$ Médias seguidas de mesma letra pertencem ao mesmo grupo pelo teste Skott \& Knott a 5\% de probabilidade.

queima (Phytophthora infestans) (Pereira et al, 2008). Da mesma forma, 'BRS Clara' apresenta ciclo vegetativo maior do que o de 'Ágata', por volta de 100 dias, na região sul do Brasil, e é resistente à requeima (Phytophthora infestans) e moderadamente resistente à pinta preta (Alternaria solani) (Pereira, 2010). Estas características contribuem para que não haja grande aumento de custos ao produtor caso seja necessário estender o seu ciclo vegetativo a campo, por conveniência de comercialização. Além disso, genótipos mais tardios, provavelmente por causa do maior tempo para realização de fotossíntese, tendem a ser mais produtivos do que os mais precoces (Silva \& Pinto, 2005; Rodrigues et al.; 2009; Silva et al., 2009).

Em geral, a produtividade de tubérculos foi maior no cultivo de primavera de 2011 do que no outono de 2012 , confirmando resultados obtidos, no Rio Grande do Sul (Bisognin et al., 2008; Andreu, 2005). A superioridade de produtividade no cultivo de primavera é atribuída à radiação solar, à temperatura média e ao fotoperíodo crescente, fazendo com que as condições climáticas desse período sejam mais propícias, para o cultivo da batata, do que as de outono (Bisognin et al., 2008; Fontes \& Finger, 1999). As condições contrastantes de primavera e outono pouco afetam o desenvolvimento das plantas de batata, mas a menor disponibilidade e eficiência de utilização da radiação solar, no outono, afetam tanto a produtividade quanto o tamanho dos tubérculos produzidos (Bisognin et al., 2008).
Apesar de ter-se destacado quanto aos tubérculos comerciais, verifica-se que o cultivar BRS Ana apresentou o menor número total de tubérculos, indicando que, para esse cultivar, os tubérculos cresceram mais do que para os outros. Isto pode ser confirmado pela maior massa média de tubérculos desse cultivar. É sabido que plantas que produzem elevado número de tubérculos apresentam, geralmente, tubérculos menores (Silva et al., 2006).

\section{CONCLUSÕES}

Nas condições de condução deste trabalho, os cultivares nacionais BRS Ana e BRS Clara apresentaram produtividade de tubérculos superior ao dos cultivares importados Asterix e Ágata, sendo, no entanto, mais tardios.

\section{REFERÊNCIAS}

Agrianual - Anuário da Agricultura Brasileira (2013) Consultoria e Agroinformativo. São Paulo, FNP. 590p.

Andreu MA (2005) Associação entre características agronômicas da batata nos plantios de primavera e outono no Rio Grande do Sul. Ciência e Agrotecnologia, 29:925-929.

Arimura NT, Carreon R, Luz JMQ, Guirelli JE Silva, PAR \& Silva MAD (2007) Influência da aplicação de produtos organominerais Aminoagro na produção de batata, cv. Ágata. Disponível em: <http:// www.abbabatatabrasileira.com.br/batatashow4/resumos.htm>. Acessado em: 11 de julho de 2012.

Bisognin da, Müller DR, Streck NA, Andriolo JL \& Sausen D (2008) Desenvolvimento e rendimento de clones de batata na primavera e no outono. Pesquisa Agropecuária Brasileira, 43:699-705. 
Costa LC, Bisognin DA, Andriolo JL, Ritter C.E.L. \& Bandinelli MG (2007) Identificação de clones de batata com potencial para mesa e adaptados para os cultivos de outono e primavera do Rio Grande do Sul. Ciência e Natura, 29:93-104.

Cruz CD (2006) Programa Genes - biometria. Viçosa, Editora UFV. 382p.

Fernandes AM, Soratto RP, Evangelista RM, Silva BL \& Souza-Schlick GD de (2011) Produtividade e esverdeamento pós-colheita de tubérculos de cultivares de batata produzidos na safra de inverno. Ciência Agronômica, 42:502-508.

Fontes PCR \& Finger FL (1999) Dormência dos tubérculos, crescimento da parte aérea e tuberização da batateira. Informe Agropecuário, 20:2429.

Gadum J, Pinto CABP \& Rios MCD (2003) Desempenho agronômico e reação de clones de batata (Solanum tuberosum L.) ao PVY. Ciência e Agrotecnologia, 27:1484-1492.

Love SL, Stark JC \& Guenthner F (2003) The origin of potato production systems. In. Stark, J.C. \& Love, S.L. Potato production system. Moscow, University of Idaho. p.1-8.

Peeten MGH, Folkertsma S, Schipper JK, Baarveld HR \& Klein S (2011) Netherlands catalogue of potato varieties. The Hague, Nivap. 285p.

Pereira A da S, Bertoncini O, Silva GO, Castro CM, Gomes CB, Hirano EO, Melo PE, Bortoletto AC, Medeiros CAB, Treptow RO, Dutra LF, Lopes CA, Nazareno NRX, Lima MF, Krolow ACR, Suinaga FA \& Reisser Junior C (2012) BRS Clara: cultivar de batata para mercado fresco, com resistência à requeima. Batata Show, 32:39-40.

Pereira A da S \& Castro CM (2010) Cultivares. In: Pereira, A. da S. (ed.) Produção de batata no Rio Grande do Sul. Sistema de Produção, 19 Pelotas, Embrapa Clima Temperado. p.39-47.
Pereira A da S \& Daniels J (2003) O Cultivo da batata na região sul do Brasil. Brasília, Embrapa Informação Tecnológica. 567p.

Pereira A da S, Silva ACF, Castro CM, Medeiros CAB, Hirano E, Nazareno NRX de, Bertoncini O, Melo PE de \& Souza Z da S (2008) Catálogo de cultivares de batata. Pelotas, Embrapa Clima Temperado. 39p. (Documentos, 247)

Pinto CABP, Teixeira AL Neder DG, Araújo RR, Soares ARO, Ribeiro GHMR \& Lepre AL (2010) Potencial de clones elite de batata como novas cultivares para Minas Gerais. Horticultura Brasileira, 28:399405 .

Resende LM de A, Mascarenhas MHT \& Paiva BM de (1999) Aspectos econômicos da produção e comercialização da batata. Informe Agropecuário, 20:9-19.

Rodrigues GB (2006) Seleção divergente para duração do ciclo vegetativo em batata. Dissertação de mestrado. UFLA, Lavras. 55p.

Rodrigues GB, Pinto CAB, Benites FRG \& Melo DS (2009) Seleção para duração do ciclo vegetativo em batata e relação com a produtividade de tubérculos. Horticultura Brasileira, 27:280-285.

Silva GO da, Souza VQ de, Pereira A da S, Carvalho FIF de \& FritscheNeto R (2006) Early generation selection for tuber appearance affects potato yield components. Crop Breeding and Applied Biotechnology, 6:73-78.

Silva LAS \& Pinto CABP (2005) Duration of the growth cycle and the yield potential of potato genotypes. Crop Breeding and Applied Biotechnology, 5:20-28.

Silva FL da, Pinto CABP, Alves D, Benites FRG, Andrade CM, Rodrigues GB, Lepre AL \& Bhering LP (2009) Caracterização morfofisiológica de clones precoces e tardios de batata visando à adaptação a condições tropicais. Bragantia, 68:295-302. 